
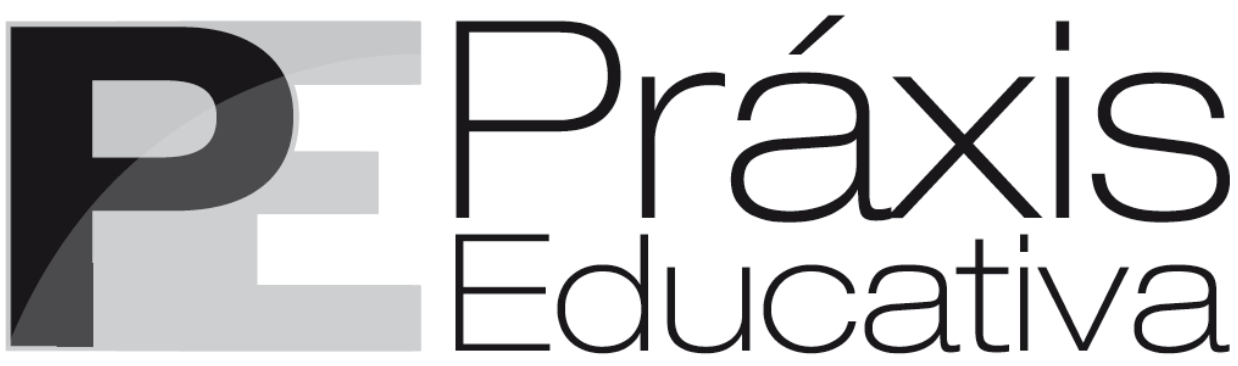

ISSN 1809-4309 (Versão online) DOI: 10.5212/PraxEduc.v.12i2.0006

\title{
Concepções pedagógicas de Educação Física: os conceitos de diferença e inclusão
}

\section{Pedagogic conceptions of Physical Education: concepts of difference and inclusion}

\section{Concepciones pedagógicas de Educación Física: los conceptos de diferencia e inclusión}

Telma Adriana Pacifico Martineli* Keros Gustavo Mileski**

Resumo: O objetivo deste artigo é analisar as teorizações pedagógicas de Educação Física e, a partir de seus pressupostos, apreender suas concepções de homem, os conceitos de diferença e, por conseguinte, de inclusão relativos a essas concepções. Trata-se de um estudo teórico que se utiliza de obras de referência da área e obras clássicas que fundamentam essas concepções. Compreende-se que a diferença e a inclusão, implícitas àquelas concepções, são concebidas a partir da biologia, da cultura, da comunicação e do trabalho, e que a prática pedagógica se orienta para fins e perspectivas também distintas. Conclui-se que é necessário avançar para além da explicação dos conceitos de diferença e de inclusão, de forma a recuperar como categoria central o trabalho, cuja explicação assenta-se na desigualdade social e na necessidade de novas e transformadoras práticas educativas para além das disseminadas nas políticas sociais e educacionais contemporâneas.

Palavras-chave: Diferença. Inclusão. Concepções pedagógicas de Educação Física.

\begin{abstract}
The aim of this paper is to analyze the pedagogical theories of Physical Education and, from its presuppositions, understand their conceptions of man, concepts of difference and inclusion relating to these conceptions. This is a theoretical study that uses reference works of the area and classical works that substantiate these conceptions. We understand that difference and inclusion, implicit in those concepts, are conceived from biology, culture, communication and work, and that teaching practice is oriented for distinct purposes and perspectives. We conclude that it is necessary to move beyond the explanations of difference and inclusion in order to recover the work as a central category, of which the explanation is based on social inequality and the need for new and transformative educational practices beyond the ones disseminated in contemporary social and educational policies.
\end{abstract}

Keywords: Difference. Inclusion. Pedagogic conceptions of Physical Education.

\footnotetext{
* Professora da Universidade Estadual de Maringá (UEM). E-mail: <telmamartineli@hotmail.com>.

** Professor no Departamento de Educação Física da Faculdade Intermunicipal do Noroeste do Paraná (FACINOR). Doutorando da Universidade Estadual de Maringá (UEM). E-mail: <kerosgustavo@gmail.com>.
} 
Resumen: Este trabajo tiene como objetivo analizar las teorizaciones pedagógicas de Educación Física y, a partir de sus presupuestos, aprehender sus concepciones de hombre, los conceptos de diferencia y, por tanto, de inclusión relativos a estas concepciones. Este es un estudio teórico que utiliza obras de referencia del área y obras clásicas que dan fundamentación a estas concepciones. Se comprende que la diferencia y la inclusión, implícitas en aquellas concepciones, son concebidas a partir de la biología, de la cultura, de la comunicación y del trabajo, y que la práctica pedagógica es utilizada para finalidades y perspectivas también distintas. Se concluye que es necesario avanzar más allá de la explicación de los conceptos de diferencia y de inclusión recobrando, para esto, el trabajo como categoría central, cuya explicación se basa en la desigualdad social y en la necesidad de prácticas educativas que sean nuevas y transformadoras más allá de las diseminadas en las políticas sociales y educacionales contemporáneas.

Palabras-claves: Diferencia. Inclusión. Concepciones pedagógicas de Educación Física.

\section{Introdução}

Este artigo é um desdobramento de estudos e de pesquisas que objetivaram a compreensão das concepções de educação e de cultura gestadas no contexto da crise estrutural do capital, das políticas e da reestruturação produtiva. As críticas à educação e, em particular, à Educação Física e seu ensino, já presentes desde os finais da década de 1970 e início da década de 1980, feitas por Carmo (1982), Medina (1983), Oliveira (1985), entre outros, denunciaram uma "crise de identidade" da área e ganharam reforço, principalmente, nos escritos de Castellani Filho (1988, 1993), Bracht (1992, 1997) e Taffarel (1993). Esse movimento de cunho mais crítico suscitou a necessidade de compreender os determinantes sociais, políticos e econômicos que estão na gênese e nos desdobramentos da história da Educação Física na contemporaneidade.

De tal necessidade, emergiram novas perspectivas que, segundo Castellani Filho (1997) e Albuquerque et al. (2007), podem ser sintetizadas nas seguintes concepções pedagógicas ou abordagens: Ensino aberto (HILDEBRANDT; LAGING, 1986); Desenvolvimentista (TANI et al., 1988); Construtivista e cognitivista (FREIRE, 1989); Cultural (DAOLIO, 1994); Sociológica (BRACHT, 1992, 1997); Crítico-emancipatória (KUNZ, 1994); e Crítico-superadora (SOARES et al., 1992). Essas diferentes abordagens pedagógicas de Educação Física concebem o homem fundamentadas em distintas perspectivas teórico-filosóficas, o que implica em formas diversas de conceber a diferença e a inclusão no contexto Educação Física escolar.

O objetivo deste artigo é analisar as teorizações pedagógicas de Educação Física e, a partir de seus pressupostos, apreender suas concepções de homem, bem como seus conceitos de diferença e de inclusão subjacentes. Trata-se de um estudo teórico que se utiliza de obras de referência das concepções pedagógicas da Educação Física, elaboradas a partir dos anos de 1990, das quais analisamos especificamente as seguintes: Desenvolvimentista, Cultural/plural, Críticoemancipatória e Crítico-superadora, das quais foram extraídas as categorias de análise, de forma a identificar as obras clássicas que fundamentam essas concepções, bem como documentos que as referenciam. O referencial teórico utilizado para a análise baseou-se em estudos que explicam a realidade do contexto da crise estrutural do capital e do processo de reestruturação produtiva como parte de uma totalidade das relações sociais.

A compreensão dos fundamentos dessas concepções faz-se necessária no atual e no complexo cenário educacional brasileiro, no qual o intenso debate de ordem acadêmicoprofissional busca fornecer subsídios para os responsáveis pela orientação desses processos pedagógicos na Educação. Retomar tais fundamentos abre o campo das possibilidades da prática pedagógica, onde ações concretas pautam-se em determinadas concepções de homem, de diferença, de inclusão que, necessariamente, implicam em um posicionamento por parte dos

Práxis Educativa, Ponta Grossa, v. 12, n. 2, p. 395-413, maio/ago. 2017 Disponível em: <http://www.revistas2.uepg.br/index.php/praxiseducativa $>$ 
professores de Educação Física acerca da realidade dos níveis de desenvolvimento e de aprendizagem dos alunos em processo de escolarização.

\section{Teorizações pedagógicas da Educação Física e suas concepções de homem}

Apresentamos a seguir, em linhas gerais, as concepções pedagógicas da Educação Física a partir de suas principais obras de referências, quais sejam: Desenvolvimentista, Cultural/plural, Crítico-emancipatória e Crítico-superadora. Buscamos apreender em seus pressupostos a concepção de homem e seus desdobramentos para o desenvolvimento humano e educacional.

\section{Concepção Desenvolvimentista}

De forte influência na Educação Física, essa concepção foi apresentada no livro Educação Física escolar: fundamentos de uma abordagem desenvolvimentista, de Tani et al. (1988) nos anos finais da década de 1980. O objetivo da abordagem é "[...] buscar nos processos de crescimento, desenvolvimento e de aprendizagem motora do ser humano esta fundamentação" (TANI et al., 1988, p. 1) para a Educação Física escolar e partem do pressuposto que: "Existe uma sequência normal nos processos de crescimento, desenvolvimento e de aprendizagem motora, isto significa que as crianças necessitam ser orientadas de acordo com estas características [...]" (TANI et al., 1988, p. 1-2).

Essa concepção utiliza-se do termo Taxionomia (o que é interessante notar, pois pode referir-se a princípios gerais da classificação científica, bem como pode referir-se ao ramo da Biologia que se ocupa da classificação natural dos seres vivos, animais e vegetais), para classificar os movimentos e as habilidades humanas da seguinte forma: Movimentos reflexos - Pré-escolar primeira à quarta série; Habilidades básicas - Pré-escolar - primeira à quarta série; Habilidades específicas - quinta à oitava série, Ensino Médio e Superior; Comunicação não verbal - quinta à oitava série, Ensino Médio e Superior (TANI et al., 1988).

As habilidades são classificadas em habilidades básicas (andar, correr, saltar, arremessar, quicar, rebater...); habilidades perceptivas (atividades motoras que envolvam a percepção do executante, por meio dos estímulos visual, auditivo, tátil e cinestésico); habilidades específicas (chute no futebol, cortada no voleibol, o arremesso à cesta e à bandeja do basquete), as quais dependem das habilidades básicas (andar, correr, saltar, arremessar, quicar, rebater...); e comunicação não verbal, isto é, atividades que permitem a expressão, tais como a dança, a ginástica rítmica desportiva e até mesmo a ginástica olímpica.

A concepção Desenvolvimentista apresenta uma sequência de desenvolvimento motor e faixa etária aproximada para cada fase de desenvolvimento (TANI et al., 1988): movimentos determinados culturalmente (a partir de 12 anos); combinação de movimentos fundamentais (7 a 12 anos); movimentos fundamentais (2 a 7 anos); movimentos rudimentares (1 a 2 anos); movimentos reflexos (vida uterina a 4 meses após o nascimento).

O tipo de avaliação: Feedback - informação sobre o movimento (TANI et al., 1988) sem que se questione se o objetivo foi alcançado e se o movimento foi executado conforme o planejado (TANI et al., 1988). Os teóricos desenvolvimentistas fundamentam-se nos estágios de Piaget - Estágio sensório-motor; Estágio pré-operacional; Estágio das operações concretas; Estágio das operações formais - e afirmam que o desenvolvimento cognitivo tem implicações na atividade motora. 
Quanto ao desenvolvimento afetivo-social, essa perspectiva concebe o homem como um ser individual que se desenvolve em uma "dinâmica relacional social" (TANI et al., 1988, p. 122). A concepção Desenvolvimentista considera o "eu" desse indivíduo como "uma composição de pensamentos e de sentimentos que constituem a consciência que uma pessoa tem de sua existência individual, sua ideia de quem é, e seus sentimentos com respeito às suas características, qualidades e propriedades. $\mathrm{O}$ “"eu' de uma pessoa é a soma de tudo o que pode ser chamado de "seu" (TANI et al., 1988, p. 122-123, grifos dos autores). Nesse sentido, o "eu" vai desenvolvendo a sua personalidade ao estabelecer relações interpessoais dentro de grupos sociais dos quais faz parte. Tais interações ocorrem no âmbito de processos sociais imbuídos de valores culturais, sobre os quais os autores salientam três processos: a competição, o conflito e a cooperação.

Aqui marcamos a concepção de homem e diferença para essa abordagem, a qual afirma que uma pessoa ou grupo pode apresentar como objetivo um melhor resultado que si mesma, outra pessoa ou grupo, o que faz emergir a competição ou conflito. A competição gera interação positiva dentro dos grupos e negativa entre os grupos. Os autores dessa concepção assinalam que a competição é percebida ao longo dos tempos, trazendo para tal afirmação uma referência bíblica. "Por exemplo, a frase 'com o suor do teu rosto ganharás o teu pão' convida o ser humano a ir à luta" (TANI et al., 1988, p. 131).

Para esses autores, tal luta no seio social pode ser explicada a partir de leis do evolucionismo biológico:

O princípio de seleção natural, por sua vez, evidencia que os homens são diferentes dentro da espécie e sobressaem por aquilo que melhor sabem e podem fazer. Esta é uma outra situação de competição, pois, dentro de um mesmo 'fazer', uma pessoa só poderá render mais que outra. Já o princípio de luta pela sobrevivência coloca o indivíduo diante de si mesmo com todas as possibilidades existentes ao seu dispor, bem como com a dúvida sobre a opção quanto a que caminho seguir. (TANI et al., 1988, p. 131, grifos dos autores).

A seleção natural e a luta pela sobrevivência são princípios biológicos aplicados à sociedade e ao desenvolvimento individual. Para os autores, a competição é naturalmente dada e não pode ser eliminada nem indevidamente ressaltada.

Já o conflito é concebido como uma forma drástica de oposição entre os indivíduos, “[...] um processo social que acentua as diferenças e diminui as semelhanças" (TANI et al., 1988, p. 131). Ocorre de forma estruturada em qualquer aspecto da sociedade, não pode ser evitado, embora seja possível usar suas vantagens, no sentido de que seus aspectos negativos sejam minimizados e os positivos enfatizados.

Os autores tratam ainda da cooperação como um processo social no qual os indivíduos interagem. Para eles, as pessoas ou grupos cooperam por um objetivo comum, e essa cooperação pode ser voluntária, altruísta, ou coercitiva quando forças externas pressionam o sujeito. Os teóricos afirmam ainda que esse processo social gera uma sensação de bem-estar, o que o fortalece em diferentes camadas da sociedade, mas: "Por outro lado, pode incrementar, em certos indivíduos, a falta de iniciativa, a dependência e um não-compromisso com os objetivos" (TANI et al., 188, p. 133). O entendimento de homem, portanto, nessa concepção, é o do homem biológico que pode ser estudado, analisado e desenvolvido de forma fragmentada em suas dimensões motora, afetivo-social e cognitiva. 


\title{
Concepção do ser Cultural/plural
}

Estudos para discutir a cultura na área da Educação Física foram levados a cabo a partir dos anos de 1980 por Medina (1983) e Oliveira (1985). Entretanto, a abordagem pedagógica cultural plural ganhou abrangência com o livro Da cultura do corpo, de Jocimar Daolio, publicado em 1994, obra que se tornou referência ao apresentar as bases dessa abordagem cultural, marcando o início dos estudos nessa vertente teórica na Educação Física brasileira. A cultura, nessa visão, é concebida como tema central e fundamento para interpretação da realidade em geral e da Educação Física em particular. Essa relação entre Educação Física e cultura é recorrente nos documentos do Estado brasileiro para a área e também expressa a dimensão política que a cultura alcançou nas últimas décadas.

Para Daolio (1994), a Educação Física é produto corporal e o corpo é determinado culturalmente. Esse autor apresenta essa abordagem como àquela que se coloca no campo da crítica, ao buscar a superação da concepção biologicista e estratigráfica de homem e de ciência. As bases da concepção cultural plural fundam-se na Antropologia Social do sociólogo francês Marcel Mauss (1872-1950) e, especialmente, na Teoria Interpretativa do antropólogo cultural norte-americano Clifford Geertz (1926-2006), principalmente em sua produção A interpretação das culturas (GEERTZ, 2011). Não obstante, outras pesquisas fundamentadas nessas teorias fizeramse presentes nos estudos atuais da área.

A perspectiva antropológica social constituiu-se no caminho teórico e metodológico que os autores dessa perspectiva cultural/plural entenderam ser cientificamente adequado para avançar no desenvolvimento de uma Educação Física na educação escolar que vá além da perspectiva biologicista e tecnicista e das práticas institucionais homogeneizadoras, características do campo pedagógico. A antropologia social "[...] pauta-se pelo estudo do homem nas suas relações sociais, entendendo-o como construtor de significados para as suas ações no mundo. Se o homem é sempre um ser social, vinculado a redes de sociabilidade, com uma grande capacidade de agir simbolicamente, ele também o é na sua atividade profissional" (DAOLIO, 1994, p. 15).

O autor reafirma a busca de uma prática que se apoie no caráter cultural do corpo com o qual trabalha e também nos conteúdos que desenvolve, ou seja, “[...] uma Educação Física que, emprestando da Antropologia o princípio da alteridade, permita considerar que todos os alunos, independentemente de suas diferenças, são iguais no direito à sua prática" (DAOLIO, 1994, p. 19). O autor explica em nota:

\begin{abstract}
A antropologia nos ensina a considerar as diferenças entre os vários grupos humanos não como desigualdades, mas como características específicas de cada grupo. Assim, fazer antropologia exige, de alguma forma, colocar-se no lugar do outro, procurando compreender sua dinâmica cultural própria. O princípio da alteridade implica a consideração e o respeito às diferenças humanas. (DAOLIO, 1994, p. 19).
\end{abstract}

No entendimento de Oliveira e Daolio (2010), a partir das pesquisas realizadas em escolas, reside na alteridade e nos pressupostos da educação intercultural "[...] uma possibilidade de enfrentamento das desigualdades de oportunidades, estereótipos, preconceitos e sectarismos ainda diluídos nos cotidianos escolares" (OLIVEIRA; DAOLIO 2010, p. 161). Os autores afirmam estar cientes das

[...] possíveis limitações, mas conscientes de que se trata de um ponto de partida para se pensar outro tipo de relação social em qualquer cenário escolar. Assim, a alteridade coloca-se na direção de um caminho possível de enfrentamento das tensões advindas da diversidade cultural, percebidas neste estudo. (OLIVEIRA; DAOLIO, 2010, p. 161).

Práxis Educativa, Ponta Grossa, v. 12, n. 2, p. 395-413, maio/ago. 2017 Disponível em: < http://www.revistas2.uepg.br/index.php/praxiseducativa > 
Para esses autores, portanto, tais tensões são culturais e são oriundas da diversidade cultural, o que justifica a defesa da alteridade e da educação intercultural como formas de diluílas.

A partir da antropologia sociocultural, tem-se outra concepção de homem, qual seja: a do homem não mais biológico, nem motor, nem social, mas do homem cultural; a da existência de culturas, e não de cultura; e a da sociedade como plural (DAOLIO, 1993, 1994, 2007). O autor pondera que a questão natureza/cultura não se mostra mais do que uma disputa, na qual se defende a predominância de uma em relação/sobre a outra. Dessa reflexão, advém a afirmação do autor de que:

\footnotetext{
Não existe homem sem natureza, da mesma forma que não existe homem sem cultura. Podemos afirmar que a natureza do homem é ser um ser cultural. E o cérebro humano é também cultural, já que ele atingiu os últimos estágios de desenvolvimento em função das primeiras aquisições culturais. (DAOLIO, 1993, p. 52).
}

Daolio (1993) apropria-se das ideias de Geertz (2011) quando afirma que "[...] sem homens certamente não haveria cultura, mas, de forma semelhante e muito significativamente, sem cultura não haveria homens" (DAOLIO, 1993, p. 52). Daolio (1993) considera a existência de uma relação direta entre "natureza e cultura humanas" com a questão do corpo. O autor afirma: "Existe um arcabouço biológico semelhante a todos os seres humanos, mas que se expressa e se desenvolve diferentemente dependendo das influências culturais" (DAOLIO, 1993, p. 52).

O autor assegura que "[...] os movimentos realizados pelo corpo humano são desenvolvidos e determinados em função de uma cultura. Desde que a criança nasce, ela é submetida a um conjunto de regras, valores e normas sociais que vão influenciando seu comportamento" (DAOLIO, 1993, p. 52), donde advém a concepção de Daolio (1993) de que o corpo do homem é construído culturalmente.

Para os autores dessa concepção, o homem e seu corpo são construídos culturalmente; a cultura se expressa pelo corpo desse homem, por meio dos símbolos, signos e significados, e reforça o dualismo corpo/espírito das concepções idealistas da filosofia, nesse caso corpo/cultura.

\section{Concepção Crítico-emancipatória}

Nessa concepção, a Educação Física é entendida como campo acadêmico que estuda o ato de "movimentar-se" humano. Proposta no início dos anos de 1990, teve como produção de referência o livro Transformação didática do esporte, de Elenor Kunz (1994), cujos objetivos são: anunciar e estimular mudanças reais e concretas, tanto na concepção de ensino e de método, como nas suas condições de possibilidade, na prática pedagógica do professor de Educação Física; entender o "pessimismo teórico" para alcançar-se um "otimismo prático"; ensinar o esporte pela sua "transformação didático-pedagógica"; tornar o ensino escolar "uma educação de crianças e jovens para a competência crítica e emancipada"; redimensionar o sentido educacional e as formas práticas de ensinar Educação Física; constituir uma nova concepção de ensino para as modalidades esportivas tradicionais, em nível escolar (KUNZ, 1994, p. 6-12).

Reflexão teórica sobre os interesses e as preocupações, no âmbito da prática, de uma metodologia de ensino baseada na concepção denominada "pedagogia crítico-emancipatória e didática comunicativa” (KUNZ, 1994, p. 15), essa concepção pedagógica fundamenta-se na Teoria Crítica da Sociedade - Escola de Frankfurt, nos estudos de Herbert Marcuse (1898-1979),

Práxis Educativa, Ponta Grossa, v. 12, n. 2, p. 395-413, maio/ago. 2017 Disponível em: <http://www.revistas2.uepg.br/index.php/praxiseducativa > 
sociólogo e filósofo alemão naturalizado norte-americano; de Max Horckheimer (1895-1973), filósofo e sociólogo alemão; e de Theodor W. Adorno (1903-1969), um filósofo, sociólogo, musicólogo e compositor alemão; bem como na Teoria da Ação Comunicativa de Jürgen Habermas, filósofo e sociólogo alemão. Com base nesse referencial teórico-filosófico, essa concepção de Educação Física faz crítica à racionalidade técnico-instrumental, entendida como aquela que fragmenta o conhecimento, provoca dicotomia entre a teoria e a prática e o distanciamento da realidade.

Nessa perspectiva, uma “[...] teoria pedagógica no sentido crítico-emancipatório precisa, na prática, estar acompanhada de uma didática comunicativa, pois ela deverá fundamentar a função do esclarecimento e da prevalência racional de todo agir educacional" (KUNZ, 1994, p. 29). A educação é compreendida como um processo em que sempre se desenvolvem ações comunicativas.

No estado inicial, tem-se uma falsa consciência do modelo do esporte de alto rendimento. A libertação da falsa consciência dar-se-á, a partir dos pressupostos de Habermas, por meio da auto-reflexão. A emancipação dos agentes sociais dá-se quando reconhecem a origem e os determinantes da dominação e da alienação, da coerção auto-imposta. $\mathrm{O}$ aluno como sujeito do processo de ensino deve ser capacitado, nessa concepção Crítico-emancipatória, para a sua participação na vida social, cultural e esportiva, o que significa não somente a aquisição de uma capacidade de ação funcional, mas a capacidade de conhecer, de reconhecer e de problematizar sentidos e significados nesta vida, por intermédio da reflexão crítica. Na concepção de Kunz (1994, p. 31): "Maioridade ou emancipação devem ser colocadas como tarefa fundamental da Educação, isto implica, principalmente, num processo de esclarecimento racional e se estabelece num processo comunicativo". O autor define esclarecimento a partir de Kant: "Esclarecimento é a saída à libertação do homem de seu estado de menoridade intelectual voluntária" (KUNZ, 1994, p. 31).

Kunz (1994) considera que, na sociedade atual, há excesso de "tutores" e "vigilantes" intelectuais sobre o desenvolvimento dos jovens, pois há um grande número "[...] de especialistas que os modernos meios de produção e reprodução cultural, os meios de comunicação, a indústria cultural e a própria educação colocam à disposição [...]" (KUNZ, 1994, p. 31). Esse autor chama de emancipação o processo desenvolvido pela educação que liberta o jovem dos limites no uso de sua razão crítica, do seu agir social, cultural e esportivo.

A razão crítica nessa perspectiva é “[...] a capacidade de avaliação e análise intersubjetiva das condições de racionalidade" (KUNZ, 1994, p. 32), e a emancipação e o esclarecimento são tarefas de uma teoria Crítica de sociedade que levam a uma transição social. Assim, no estado inicial, o sujeito apresenta tanto falsa consciência (auto-ilusão) e erro quanto à existência sem liberdade (coerção auto-imposta); no estado final, os agentes estão livres de falsa consciência eles foram esclarecidos - e livres da coerção auto-imposta - eles foram emancipados.

Fundamentado na Teoria Crítica, o autor afirma que a emancipação só será possível quando os agentes sociais, pelo esclarecimento, reconhecerem a origem e os determinantes da dominação e da alienação. Os agentes sociais são levados assim a um processo de aprendizagem de auto-reflexão que deve corresponder ao interesse emancipatório do conhecimento, pela remoção da repressão e pela dissolução da falsa consciência. Cabe ao professor "[...] exigir que os alunos lutem contra a 'falsa consciência e ilusões objetivas"' (KUNZ, 1994, p. 33).

$\mathrm{Na}$ especificidade do ensino do esporte, na Educação Física escolar, em vez de dirigir-se ao simples desenvolvimento de habilidades e técnicas do esporte, em uma concepção críticoemancipatória, "[...] deverá ser incluído conteúdos de caráter teórico-prático que, além de tornar

Práxis Educativa, Ponta Grossa, v. 12, n. 2, p. 395-413, maio/ago. 2017 Disponível em: <http://www.revistas2.uepg.br/index.php/praxiseducativa $>$ 
o fenômeno esportivo mais transparente, permite aos alunos melhor organizar a sua realidade de esporte, movimentos e jogos de acordo com as suas possibilidades e necessidades" (KUNZ, 1994, p. 35).

Para além do trabalho produtivo de treinar habilidades e técnicas, devem ser considerados dois outros aspectos, ressalta Kunz (1994): a interação social, que valoriza o trabalho coletivo de forma responsável, cooperativo e participativo; e a orientação de uma didática comunicativa, que é a própria linguagem, pois todo o "ser corporal" do sujeito se torna linguagem - a linguagem do "se movimentar" como diálogo com o mundo.

O ensino segue um processo racionalmente organizado e sistematizado para alcançar uma melhor performance física e técnica para as práticas esportivas. Isso se caracteriza como um ensino "fechado" e, ao contrário, deve conduzir-se para o ensino democraticamente. O ensino deve capacitar para um agir solidário nos princípios de co e autodeterminação, linguagem por gestos, falada, por imitação. É

[...] pela interação e linguagem que o conhecimento técnico, cultural e social do esporte é compreendido sem ser 'imposto' de fora, e na sua 'transformação didática' devem ser respeitados os conteúdos do 'mundo vivido' dos participantes para as condições de um entendimento racional, que se dá no nível comunicativo da intersubjetividade, possa ser alcançado (KUNZ, 1994, p. 36, grifos do autor).

Essa concepção de ensino deve-se concentrar nas formas de relacionamento social entre os participantes e enfatizar trabalho (fazer), interação (relacionar) e linguagem (comunicar). Nessa perspectiva, o ensino visa o desenvolvimento de três competências, a saber: competência objetiva, cujo ensino segue um processo racionalmente organizado e sistematizado; competência social, em capacitar para o agir solidário, cooperativo e participativo (interação); competência comunicativa, em saber comunicar-se e entender a comunicação do outro, na qual o aluno consiga passar da fala comum para o nível do discurso. "[...] todos tem a oportunidade de expressar suas ideias, intenções e sentimentos” (KUNZ, 1994, p. 40).

A transformação didático-pedagógica do esporte, como concebe Kunz (1994), ocorre, inicialmente, pela identificação do significado central do ato de "se-movimentar" de cada modalidade esportiva e orienta-se segundo os seguintes passos: a encenação, a problematização, a ampliação e a reconstrução. Busca do "conhecimento de si" à medida que o processo educacional crítico-emancipatório que não se resume apenas no saber-fazer, mas também "no saber-pensar e um saber-sentir" (KUNZ, 1994, p. 68).

Nessa perspectiva, prevalece a concepção de homem emancipado, ou seja, o indivíduo atinge sua maturidade racional por meio do diálogo, uma vez que, na ação comunicativa, ele desenvolve as competências da linguagem, do trabalho e do discurso, tornando-se esclarecido e crítico, adaptando-se à sociedade.

\section{Concepção Crítico-superadora}

O livro de referência dessa concepção é Metodologia do Ensino de Educação Física (SOARES et. al., 1992), produzido por um coletivo de autores no ano de 1992, os quais consideram que a disciplina pedagógica Educação Física tem como objeto de estudo temas inerentes a cultura corporal - os mesmos que historicamente a compõem nas formas de manifestação de jogos, de lutas, de ginástica, de dança e de esporte. 
Parte do entendimento de que: "Nas sociedades de classe, como é o caso do Brasil, o movimento social se caracteriza, fundamentalmente, pela luta entre as classes sociais a fim de reafirmarem seus interesses" (SOARES et al., 1992, p. 23). Os interesses imediatos da classe trabalhadora, na qual se incluem as camadas populares, correspondem "[...] à necessidade de sobrevivência, à luta no cotidiano, ao emprego, ao salário, à alimentação, ao transporte, à habitação, à saúde, à educação, enfim, às condições dignas de existência". Já os interesses da classe proprietária correspondem, por outro lado, às suas necessidades de "[...] acumular riquezas, gerar mais renda, ampliar o consumo, o patrimônio, etc.". Sua luta é pela manutenção do status quo, sem a pretensão de transformar a sociedade brasileira, nem abrir mão de seus privilégios como classe. Para isso, a classe proprietária desenvolve determinadas formas de consciência social (ideologia), para veicular seus interesses, seus valores, sua ética e sua moral.

Os autores da teoria/concepção Crítico-superadora afirmam que o interesse da classe trabalhadora vem se expressando por intermédio da "[...] luta e da vontade política para tomar a direção da sociedade, construindo a hegemonia popular" (SOARES et al., 1992, p. 24), por meio de uma ação prática, no sentido da transformação da sociedade, de forma que os trabalhadores possam usufruir do resultado de seu trabalho. Essa concepção pedagógica concebe, portanto, que os interesses de classe são diferentes e antagônicos, já que

[...] não se pode entender que a sociedade capitalista seja aquela onde os indivíduos buscam objetivos comuns, nem tampouco que a conquista desses objetivos depende do esforço e do mérito de cada indivíduo isolado. Esse entendimento mascara a realidade social e o conflito entre as classes sociais no movimento de afirmação dos seus interesses. (SOARES et al., 1992, p. 24).

Nessa concepção de Soares et al. (1992, p. 25), o projeto pedagógico representa uma intenção, ação deliberada, estratégia; é político "[...] porque expressa uma intervenção em determinada direção e é pedagógico porque realiza uma reflexão sobre a ação dos homens na realidade explicando suas determinações". Nesse entendimento, todo educador deve ter definido o seu projeto político-pedagógico, e essa definição orientará a sua prática no nível da sala de aula: “[...] a relação que estabelece com os seus alunos, o conteúdo que seleciona para ensinar e como o trata científica e metodologicamente, bem como os valores e a lógica que desenvolve nos alunos" (SOARES et al., 1992, p. 25).

Os autores dessa perspectiva defendem o prevalecer da "diretividade pedagógica", fundamentando-se no filósofo francês e estudioso da pedagogia George Snyders (1917-2011), para quem cabe ao professor explicitar, a priori, a intencionalidade de sua ação pedagógica, pois ela não é neutra, ao contrário, pode ser caracterizada em três maneiras, quais sejam: diagnóstica, pois parte de uma "leitura"/interpretação da realidade, de uma determinada forma de estar no mundo; judicativa, já que estabelece juízo de valor, "[...] julga a partir de uma ética que representa os interesses de determinada classe social" (SOARES et al., 1992, p. 25); e, finalmente, teleológica, ou seja, determina um alvo onde se quer chegar e é "ensopada" de metas, de fins a alcançar (SOARES et al., 1992).

Essa teorização de Educação Física parte da concepção de currículo ampliado, e a ação pedagógica tem no conhecimento sobre a realidade manifesta pelo aluno o seu ponto de partida. Tem como horizonte do trabalho pedagógico a qualificação do conhecimento do aluno sobre aquela mesma realidade, no sentido de dotá-la de maior complexidade (é a mesma...e é diferente). Uma nova compreensão dessa realidade social pressupõe "[...] um novo entendimento que supere o senso comum, o professor orientará, através dos ciclos, uma nova leitura da realidade pelo aluno, com referências cada vez mais amplas" (SOARES et al., 1992, p. 87). O próprio aluno reformula seu entendimento sobre a realidade, cujos passos são: “[...] constatar, interpretar,

Práxis Educativa, Ponta Grossa, v. 12, n. 2, p. 395-413, maio/ago. 2017 Disponível em: <http://www.revistas2.uepg.br/index.php/praxiseducativa $>$ 
compreender e explicar, momentos estes que conduzem à apropriação de um conteúdo pelos alunos" (SOARES et al., 1992, p. 28).

Esse coletivo de autores preconiza outra estrutura para o processo de escolarização, centrada na ideia de Ciclos de Escolarização, fundamentando-se em teóricos histórico-culturais como: Davídov (1930-1988), Leontiev (1903-1979) e Vygotsky (1896-1934). Os ciclos de escolarização, com base nos estudos de Davídov (1988), são: $1^{\circ}$ (pré-escola à $3^{\mathrm{a}}$ série): Ciclo de organização da identificação dos dados da realidade (visão sincrética da realidade; $2^{\circ}$ Ciclo $\left(4^{a}\right.$ à $6^{a}$ série): Ciclo de iniciação à sistematização do conhecimento (o aluno vai adquirindo a consciência de sua atividade mental, suas possibilidades de abstração, confronta os dados da realidade com as representações do seu pensamento sobre eles. Dá um salto qualitativo quando começa a estabelecer generalizações); $3^{\circ}$ Ciclo ( $7^{a}$ à $8^{a}$ série): Ciclo de ampliação da sistematização do conhecimento (o aluno amplia as referências conceituais do seu pensamento; ele toma consciência da atividade teórica - salto qualitativo: propriedade da teoria); $4^{\mathrm{o}}$ Ciclo: ( $1^{\mathrm{a}}$ à $3^{\mathrm{a}}$ série): Ciclo de aprofundamento da sistematização do conhecimento (o aluno adquire uma relação especial com o objeto, que lhe permite refletir sobre ele. $\mathrm{O}$ aluno lida com a regularidade científica e pode adquirir algumas condições para ser produtor de conhecimento científico). Soares et al. (1992) adotam como referências teóricas, também, os estudos de Leontiev (1981) e Vygotsky $(1984,1987)$, no que se refere ao desenvolvimento do psiquismo.

Os princípios curriculares e de seleção dos conteúdos orientam-se pela sua relevância social, contemporaneidade, adequação às capacidades sócio-cognoscitivas do aluno, simultaneidade dos conteúdos como dados da realidade, espiralidade da incorporação das referências de pensamento, provisoriedade do conhecimento. Os conteúdos jogos, ginástica, esporte, lutas, como indicam os autores, são selecionados, organizados e sistematizados e devem promover uma concepção científica de mundo, a formação de interesses e a manifestação de possibilidades e aptidões para conhecer a natureza e a sociedade. Para isso, o método deve apontar "[...] o incremento da atividade criadora e de um sistema de relações sociais entre os homens" (SOARES et al., 1992, p. 87).

A metodologia funda-se na intenção prática do aluno para apreender a realidade, assim "[...] a aula constitui-se como espaço intencionalmente organizado para possibilitar a direção da apreensão, pelo aluno, do conhecimento específico da educação física e dos diversos aspectos de sua prática na realidade social". Ao aproximar o aluno da totalidade, "[...] permite articular uma ação (o que faz), com o pensamento sobre ela (o que pensa) e com o sentido que dela tem (o que sente)" (SOARES et al., 1992, p. 87). O sentido de avaliação do processo ensino-aprendizagem em Educação Física, nessa perspectiva pedagógica, é o de fazer com que ela sirva de referência para a análise de aproximação ou distanciamento do eixo curricular que norteia o projeto pedagógico da escola.

Nessa concepção, o homem é considerado a partir de sua perspectiva de classe, com foco nas necessidades da classe trabalhadora, na qual se incluem as classes populares. Para essa concepção, o desenvolvimento humano está vinculado ao desenvolvimento social, à consciência de classe e à apropriação da produção humana.

\section{A Educação Física, as políticas de inclusão no contexto da crise do capital}

Explicitamos, nesse tópico, as concepções de diferença e de inclusão a partir da compreensão da conjuntura histórica na qual essas concepções emergiram implícitas nas concepções de homem. A conjuntura da crise é o pano de fundo das reformas estruturais nos

Práxis Educativa, Ponta Grossa, v. 12, n. 2, p. 395-413, maio/ago. 2017 Disponível em: < http://www.revistas2.uepg.br/index.php/praxiseducativa > 
países alinhados ao sistema capitalista, com profundas implicações econômicas, políticas e sociais para os países periféricos e em seus modelos de educação, como ocorreu no Brasil.

A educação brasileira, no início da década de 1980, período de reabertura democrática pós-ditadura militar, frente às desigualdades sociais, econômicas e de baixo nível de desenvolvimento educacional e humano, tem como desafio a busca por novas perspectivas de compreensão dessa realidade e das novas necessidades do sistema produtivo para o enfrentamento da crise. Pesquisadores e educadores mobilizaram-se por meio de congressos, fóruns e seminários, promovidos por associações, colégios, universidades, entre outras instituições ligadas à educação, o que resultou em teorizações e concepções pedagógicas.

Nesse contexto, a produção de conhecimentos científicos na área da Educação Física ampliou-se gradativamente, resultante dos estudos e das pesquisas sobre a história da Educação Física, metodologias de ensino, teorias pedagógicas e de outras temáticas que passaram a veicular no contexto científico e editorial de forma mais expressiva, ainda que inicialmente, "novos fundamentos". Esse movimento pressionou o Estado, no sentido de promover reformas educacionais, bem como influenciou as ações pedagógicas no âmbito escolar. O que se colocava em pauta era a superação dos "velhos paradigmas", sobretudo o mecanicismo do pensamento biologicista de cunho positivista, predominante na concepção de homem, nas discussões pedagógicas e metodológicas da Educação Física e na prática pedagógica implícita nesse pensamento. Entretanto, esse movimento renovador não implicou em uma completa ruptura com os "velhos paradigmas", mas possibilitou inclusive continuidades nas práticas pedagógicas.

As concepções biologicistas sustentam, ainda hoje, o pensamento tanto dentro como fora da escola, justificando as práticas pedagógicas que concebem "uma sequência normal nos processos" (TANI et al., 1988, p. 1) de desenvolvimento humano e possibilitam a prática pedagógica da Educação Física na busca de talentos esportivos, de atividades direcionadas para um nível "normal" das habilidades, não concebendo que existem diferenças individuais. Fundada nessa concepção, a inclusão é impossibilitada, pois, em sua raiz, encontra-se o princípio da exclusão. O desenvolvimento ocorre em nível individual e, dentro de um padrão "normal" préconcebido, se o sujeito não se adapta socialmente, encontra-se excluído do processo social e educacional.

Contrapondo-se a essas concepções biológicas de homem, a abordagem cultural concebe o homem como um ser cultural que, embora biológico, existe na relação natureza/cultura. Para essa abordagem, a determinação cultural irá influenciar direta e diferentemente o desenvolvimento do arcabouço biológico humano que se "expressa pelo corpo", construindo os significados para a ação do homem no mundo. É esse "diferente desenvolvimento", culturalmente determinado, que explica as desigualdades de oportunidades, preconceitos, estereótipos e reforça, na Educação Física, o conjunto de ideias amplamente disseminado naquele período de valorização das culturas, de respeito à diversidade cultural, à pluralidade e à alteridade. Fundamentada nessa concepção, a prática pedagógica da Educação Física concebe as diferenças dos indivíduos a partir da "dinâmica cultural própria" e a inclusão é tratada no sentido do respeito à diversidade cultural.

Paralelamente a essa perspectiva cultural, a abordagem Crítico-emancipatória concebe o homem como um ser social que se desenvolve a partir dos signos e significados da linguagem. É por meio da comunicação que o indivíduo se desenvolve racionalmente, rompendo com a "falsa consciência", culturalmente imposta no "mundo vivido" por uma "coerção auto-imposta", tornando-se esclarecido e emancipado. O aluno, ao atingir uma "maturidade intelectual", passa a compreender as relações e as contradições nelas presentes, passando a atender as diferentes expectativas sociais e a resolver os problemas sociais no campo do discurso, expressando suas

Práxis Educativa, Ponta Grossa, v. 12, n. 2, p. 395-413, maio/ago. 2017 Disponível em: < http://www.revistas2.uepg.br/index.php/praxiseducativa > 
ideias e seus sentimentos. A diferença é explicada pelo fato de atingir ou não essa maioridade intelectual, ao passo que a inclusão é dada por meio da ação dos agentes sociais no reconhecimento das origens e dos determinantes da dominação e da alienação. A prática pedagógica é concebida como aquela que exige dos indivíduos uma luta contra a "falsa consciência e ilusões objetivas" e, de acordo com as possibilidades e necessidades dos alunos, o esporte é transformado (KUNZ, 1994, p. 33).

Destoando das concepções anteriores, a concepção Crítico-superadora concebe o homem a partir de sua condição de classe. A diferença é explicada a partir dos interesses antagônicos dessas classes. A classe trabalhadora destituída dos meios de produção luta pela sobrevivência por vender sua força de trabalho à classe proprietária, que expropria daqueles a riqueza por eles produzida. A inclusão não se dá na perspectiva do "esforço ou do mérito" individual, mas na luta pelo interesse da classe trabalhadora, no sentido de transformar a sociedade para que possa usufruir do resultado de seu trabalho, cujo pressuposto é a apropriação pelo aluno dos conhecimentos historicamente produzidos da cultura corporal.

Uma análise histórica dessas concepções pedagógicas em seus nexos com a totalidade das relações sociais capitalistas atreladas às necessidades específicas do momento social eeconômico contemporâneo permite compreender que o marco histórico de referência para pensadores como Mézsáros (2008 e 2009) e Harvey (2004 e 2012) e, no Brasil, Tonet (2007), Netto e Braz (2007), situa-se na transição da década de 1960 , momento em que a crise começa a assolar o sistema global do capital.

No entendimento de Mészáros (2009), essa crise arrasta-se em um continuum, e, embora aparentemente superada entre os anos de 1990 e 2008, por meio do aprofundamento do padrão de globalização capitalista baseado na utilização do controle militar planetário dos Estados Unidos, acabou por determinar a quebra do sistema financeiro de 2008 (MÉSZÁROS, 2009; HARVEY, 2012). O anterior modelo produtivo de automação rígida não mais atendia à reprodução e à acumulação capitalista, culminando nos processos destrutivos resultados da Guerra e na subsequente criação dos organismos internacionais como mecanismos de reconstrução dos países e recomposição das estruturas sociais e políticas, a exemplo do Banco Internacional de Reconstrução e Desenvolvimento, do Banco Mundial, do Fundo Monetário Internacional, da UNESCO.

Distanciando-se das explicações econômicas, esses organismos passaram a combater as ideias positivistas e o evolucionismo social. A linguagem, a comunicação, a cultura, passaram a ser categorias importantes na compreensão e na explicação da realidade social e da concepção de homem. Desse modo, a centralidade da cultura estabeleceu os fundamentos das concepções de identidade humana, de etnias, de diferença e de diversidade cultural. Sob os auspícios do multiculturalismo e da interculturalidade (FAUSTINO, 2006), como condicionalidades desses órgãos, as políticas inclusivas foram o foco das reformas nacionais, a partir dos anos de 1970, e implicaram diretamente nas reformas neoliberais da década de 1980 e nas reformas políticas culturais, artísticas e educacionais da década de 1990. A "agenda globalmente estruturada para a educação" (DALE, 2004) tomou a escola como o principal lócus de atuação e evidenciou a diversidade, a diferença e a inclusão como conceitos a serem implementados no campo da educação e, mais especificamente, da Educação Física. Entretanto, a centralidade da cultura, disseminada pela ideologia neoliberal e pós-moderna por meio dos organismos internacionais e nacionais, ganha uma centralidade na explicação da realidade, ao passo que outras concepções persistem no sentido de reafirmar uma visão conservadora e reacionária.

As ideias biologicistas reafirmam-se, desenvolvendo e reelaborando suas explicações e suas práticas sociais e educacionais, como as que fundamentam a concepção pedagógica 
desenvolvimentista. Essa concepção historicamente percorreu o desenvolvimento moderno da Educação Física em bases positivistas de ciência e, ainda hoje, é defendida e fundamenta ações pedagógicas na escola. Essas explicações servem, até os dias atuais, "[...] de fundamento teórico às teses pseudobiológicas mais reacionárias e mais racistas" (LEONTIEV, 2004, p. 261), pois justifica as diferenças de raças, de condição social, de desenvolvimento das habilidades para formar um indivíduo dócil e adaptado necessário ao modelo produtivo.

Contrapondo-se a essa perspectiva e em defesa da cultura e da diversidade cultural, da educação multicultural e intercultural e sua influência na configuração da concepção de Educação Física humanística da década de 1980, a concepção Cultural/plural tornou-se referência nas teorizações e nas disposições legais para a área de Educação Física no Brasil, orientando-se pelos mesmos princípios disseminados pelos organismos internacionais, especialmente a UNESCO (1966, 1997, 2002) e nacionais. A concepção de homem, de cultura e de sociedade de cunho idealista-fenomenológico alicerça ideologicamente a reestruturação produtiva nesse momento de crise do capital. Todavia, sem questionar a real origem econômica e social desses problemas, desconsideram-se as possibilidades de transformação social que possibilitaria a inclusão real ao tornar todos os seres humanos economicamente iguais e humanamente diferentes entre si.

Outras concepções foram elaboradas como resposta ao contexto de crise, no campo da "crítica", porém reprodutivista, como a concepção Crítico-emancipatória. No bojo dessa perspectiva cultural, essa concepção responde às necessidades de um discurso de crítica em uma sociedade democrática, que não se diferencia das outras duas vertentes anteriormente apresentadas. Os autores dessas concepções enfatizam as relações indivíduo-sociedade/ sociedade-indivíduo, embora reforcem a necessidade de tratar o indivíduo como parte de uma globalidade. Por meio dessa cisão indivíduo/sociedade, reforçam a visão de que os homens são mônadas isoladas (MARX, 2010) que estão cooperando ou competindo umas com as outras em constante luta pela sobrevivência, em uma sociedade naturalmente dada e impossível de ser transformada. Assim, suas personalidades e seu eu se formam de maneira isolada, em pequenos grupos particulares, reforçando o caráter de diferença e possibilitando a inclusão apenas quando o grupo interage com um objetivo local comum, como a prática esportiva, por exemplo.

Elaborada no sentido de contrapor essas ideias conservadoras e apontar para outro projeto histórico, a concepção Crítico-superadora orienta seus pressupostos metodológicos a partir da afirmação da existência de uma luta de classes. Nesse sentido, a diferença é explicada na pertença a uma dessas duas classes antagônicas, e a inclusão é possibilitada na formação do aluno como sujeito pertencente a uma dessas classes. No contexto da crise estrutural, ao fundamentarse em uma perspectiva crítica das relações sociais, essa concepção chama a atenção para a explicação das diferenças como oriundas das determinações econômicas e sociais e não das determinações biológicas e culturais/naturais. Em tempos em que se busca o consenso e a subserviência dos indivíduos para a recomposição das forças trabalhadoras, a concepção Críticosuperadora coloca-se na contra-mão do pensamento hegemônico.

As análises e os estudos dessas concepções pedagógicas de Educação Física possibilitaram aprender suas concepções de homem e os conceitos de diferença e inclusão subentendidos. Consideramos de fundamental importância aprofundar essas análises recuperando os fundamentos na Teoria Histórico-Cultural, como pressuposto para avançar para além das perspectivas Biologicista, Culturalista e Crítico-emancipadora e, também, contribuir com os debates e os avanços na perspectiva Crítico-superadora.

Práxis Educativa, Ponta Grossa, v. 12, n. 2, p. 395-413, maio/ago. 2017 Disponível em: <http://www.revistas2.uepg.br/index.php/praxiseducativa > 


\section{Da “diferença" para a desigualdade, da “inclusão" para a humanização: algumas considerações}

A primeira concepção que nos parece suscitar questionamento é a concepção de "diferença", pois ao tentarmos fundamentar determinada concepção de homem parece não existir uma unidade na espécie humana. A diversidade, isto é, a "diferença" apresenta-se de modo inegável nos mais distintos traços e é tomada como objeto central das análises, cujas explicações se limitam aos traços biológicos ou culturais particulares e subjetivos. Diferentes teorias debruçaram-se a explicar ou justificar essas "diferenças" humanas a partir de diferentes pressupostos. Como explicitamos anteriormente, no contexto da crise e da reestruturação capitalista, essas explicações reducionistas e intencionais tornam-se verdades inquestionáveis.

Já na primeira metade do século XX, Leontiev (2004) afirmava que a realidade de desigualdade entre os homens, de pobreza de continentes inteiros, de deficiências humanas de ordem física e intelectual e de baixo desenvolvimento humano das populações mais pobres, especialmente negras e indígenas, em detrimento da riqueza e do desenvolvimento humano de outras populações, especialmente das populações dos países ricos, "[...] não provém das suas diferenças naturais" (LEONTIEV, 2004, p. 293), como explicam as concepções biologicistas. Essa realidade, que permanece muito atual, na verdade é "[...] produto da desigualdade econômica, da desigualdade de classes e da diversidade consecutiva das suas relações com as aquisições que encarnam todas as aptidões e faculdades da natureza humana, formadas no decurso de um processo sócio-histórico" (LEONTIEV, 2004, p. 293-294). A separação entre as aquisições do desenvolvimento histórico daqueles que criam esse desenvolvimento ocorre, no entendimento de Leontiev (2004, p. 294), "[de] forma prática na alienação econômica dos meios e produtos do trabalho em face dos produtores diretos", decorrente da divisão social do trabalho, nas formas da propriedade privada e da luta de classes.

Explica Leontiev (2004, p. 294, grifos do autor) que, “[...] enquanto globalmente a atividade do homem se enriquece e se diversifica, a [atividade] de cada indivíduo tomado à parte estreita-se e empobrece". A concentração das riquezas materiais e intelectuais nas mãos de uma classe dominante é acompanhada da expropriação dessas riquezas e um mínimo acesso a elas, por parte das massas e das classes populares. Essa concentração e a estratificação da cultura não se produzem apenas no interior das nações ou dos países, mas, como explica Leontiev (2004, p. 294), "[...] a desigualdade de desenvolvimento cultural dos homens manifesta-se ainda mais cruamente à escala do mundo, da humanidade inteira".

É essa desigualdade que serve, na maioria das vezes, para justificar uma distinção entre os representantes das raças superiores e inferiores, como afirma Leontiev (2004). Os países onde se fazem os maiores esforços neste sentido são aqueles em que “[...] as classes dirigentes estão particularmente interessadas em dar uma justificação ideológica ao seu direito a submeter povos menos avançados no seu desenvolvimento econômico e cultural" (LEONTIEV, 2004, p. 296), constituindo a base material em que se assentaram o "[...] racismo e, apoiado nele, o preconceito existente na realidade social" (SILVA, 2012, p. 12).

Essa imposição de limites estendeu-se aos indivíduos das populações negras, indígenas, femininas e tantos outros, e, agora, os mais diversos grupos de etnias e religiões pertencentes às populações mais pobres. Essas chamadas "minorias" são os que se tornaram foco de direcionamento e disseminação do pensamento e da política da diversidade cultural gerada pelo próprio sociometabolismo do capital (MÉSZÁROS, 2009). Essa "política" configurou-se, em última análise, como forma de promover a coesão e focalizou a educação como forma de promover o desenvolvimento social e local (FONSECA, 1998).

Práxis Educativa, Ponta Grossa, v. 12, n. 2, p. 395-413, maio/ago. 2017 Disponível em: <http://www.revistas2.uepg.br/index.php/praxiseducativa $>$ 
A raiz da problemática - os limites dos desenvolvimentos humanos nos mais diferentes contextos da sociedade capitalista - expressa-se mais especificamente na realidade escolar. Crianças, jovens e adultos, pelas condições sociais, excluídos economicamente do acesso à riqueza, à técnica artística, cultural, científica acumulada pela humanidade têm comprometido o seu desenvolvimento, pois é a apropriação dessa produção humana que possibilita o desenvolver de suas capacidades. Esses comprometimentos, que são de origem econômica, expressam-se nas mais variadas formas de dificuldades, das quais as mais evidentes são as de aprendizagem que demandam processos educativos específicos, uma vez que são tomados como diferenças humanas e precisam ser enfrentados pela educação, na qual a educação inclusiva tende a ser a panaceia para a resolução desses problemas.

Embora seja uma realidade que pode ser enfrentada na escola, é preciso compreender que o que está na raiz das diferenças e nos seus contrastes não é a diferença cultural, como afirmam os antropólogos e os estudiosos da cultura na atualidade, mas sim a condição de classe e a diferença entre quem detém os meios de produção e as riquezas produzidas e quem é explorado e impossibilitado de se apropriar das aquisições da cultura humana.

Compartilhamos do posicionamento de Silva (2012) de que é necessário recuperar a concepção de gênero humano como ela foi concebida originariamente por Marx e Engels (2007) e aprofundada por Lukács (2010), como resultado da gênese do ser social no salto ontológico realizado a partir do trabalho. É necessário nos entendermos como pertencentes ao gênero humano e, como tal, lutarmos pela emancipação humana, pela igualdade e contra as desigualdades. Netto (2011, p. 2) afirma: "Hoje, mais do que nunca, estou convencido de que é possível construir uma sociedade igualitária e, porquanto igualitária, que possa garantir as diferenças, porque o contrário da igualdade é a desigualdade e não a diferença”".

A Educação Física pode dar sua contribuição nessa realidade complexa, e todas essas dificuldades humanas que estão presentes na escola podem ser superadas. Isso pode dar-se pela valorização da mediação do professor, na sistematização dos conhecimentos científicos ao longo das séries para que os alunos consigam atingir conceitos mais elaborados na explicação da realidade. Os conteúdos da Educação Física, como os jogos, as brincadeiras, as ginásticas, os esportes e as lutas, têm um potencial para o desenvolvimento dos alunos nas diferentes etapas do processo de escolarização. Ao mesmo tempo que os alunos podem apropriar-se das formas tradicionais e históricas dessas práticas, as mais avançadas técnicas, táticas, elaborações culturais e científicas possibilitam o desenvolvimento pleno das capacidades humanas dos alunos.

Retomando a concepção de Leontiev (2004), compreendemos que o homem é um ser social e que o seu devir humano provém de sua vida em sociedade e da cultura criada pela humanidade, portanto o indivíduo aprende a ser homem ao adquirir o que foi desenvolvido no decurso da história humana. Nesse sentido, a prática pedagógica da Educação Física ao utilizar os componentes da cultura corporal - o jogo, o esporte, a ginástica, a dança - como formas de atividades historicamente construídas, contribuirá no sentido de que quanto mais ricas forem as experiências sócio-históricas dos alunos, maiores serão as suas capacidades de apropriarem-se e reelaborarem essas experiências de forma criadora. O professor tem um papel fundamental nesse processo, como mediador, orientando e direcionando os alunos em seus estudos e ações. As funções psíquicas superiores, psicomotoras, como a imaginação, a memória, a atenção, bem como as físicas e motoras, como o equilíbrio, a coordenação, a flexibilidade, a agilidade, entre outras, devem ser potencializadas na infância para o desenvolvimento da capacidade criativa, técnica e da subjetividade humana. Fundamentado nessa teoria, o trabalho pedagógico pode favorecer o desenvolvimento em sua totalidade.

Particularmente para o ensino da Educação Física, são muitas as contribuições da Teoria

Práxis Educativa, Ponta Grossa, v. 12, n. 2, p. 395-413, maio/ago. 2017 Disponível em: < http://www.revistas2.uepg.br/index.php/praxiseducativa > 
Histórico-Cultural, pois preconiza o ensino intencionalmente organizado que deve proceder a seleção dos conteúdos da Educação Física com objetivo de possibilitar e contribuir com o devir humano de seus alunos, mobilizando-os e abrindo caminho para o amplo desenvolvimento de suas capacidades humanas. Somente assim a Educação Física pode avançar para contribuir na construção de outro projeto histórico, ao possibilitar a formação de pessoas que caminhem no sentido de uma autêntica comunidade humana.

\section{Considerações finais}

A análise histórica das concepções pedagógicas da Educação Física possibilita apreender a concepção de homem e, a partir dela, as concepções de diferença e de inclusão subjacentes as suas elaborações teóricas de referência. As análises centraram-se nas categorias que orientaram tais teorizações, quais sejam: a biologia, na concepção Desenvolvimentista; a cultura, na concepção Cultural/plural; a linguagem e a comunicação, na concepção Crítico-emancipatória, e a luta de classes, na concepção Crítico-superadora.

Concluímos que é necessário compreender essas concepções em seus nexos com a totalidade das relações sociais e da crise do capital, cujo acirramento das tensões e das contradições econômicas, sociais e políticas e o argumento da biologia voltam a justificar a diferença. Além disso, a cultura e a defesa da diversidade cultural e da alteridade que trouxeram implicações para a educação e também para a Educação Física como componente curricular da educação.

É necessário também avançar para além das categorias da biologia, da comunicação e da linguagem como explicação da diferença e da inclusão na realidade social e educacional, tomando como categoria central o trabalho, cuja explicação se assenta na desigualdade social e na necessidade de novas e transformadoras práticas educativas para além das exaustivamente disseminadas nas políticas sociais e educacionais.

Consideramos que, dentre as concepções analisadas, a Crítico-superadora é aquela que mais avançou na concepção de homem e seus desdobramentos no entendimento de diferenças e inclusão, pois se fundamenta na categoria trabalho, embora esta não seja tomada em sua radicalidade histórica. Isso representa um limite teórico e pedagógico, o qual expressa uma concepção pedagógica carente de maiores debates acadêmico-profissionais e proposições metodológicas mais avançadas.

\section{Referências}

ALBUQUERQUE, J. O. et al. A prática pedagógica da Educação Física no MST: possibilidades de articulação entre teoria pedagógica, teoria do conhecimento e projeto histórico. Revista Brasileira de Ciências do Esporte, Campinas, v. 28, n. 2, p. 121-140, jan. 2007.

BRACHT, V. Educação Física e aprendizagem social. Porto Alegre: Magister, 1992.

BRACHT, V. Sociologia crítica do esporte: uma introdução. Vitória: CEFD/UFES, 1997.

CARMO, A. A. Educação Física, crítica a uma formação acrítica: um estudo das habilidades e capacidades intelectuais solicitadas na formação do professor de Educação Física. 1982. 159 f. Dissertação (Mestrado em Educação) - Universidade Federal de São Carlos, São Carlos, 1982. 
CASTELLANI FILHO, L. Educação Física no Brasil: a história que não se conta. Campinas: Papirus, 1988.

CASTELLANI FILHO, L. Pelos meandros da Educação Física. Revista Brasileira de Ciências do Esporte, Ijuí, v. 14, n. 3, p. 119-125, maio 1993.

CASTELLANI FILHO, L. Projeto de reorganização da trajetória escolar no ensino fundamental: uma proposta pedagógica para a Educação Física. Revista da Educação Física, Maringá, v. 8, n. 1, p. 11-19, 1997.

DALE, R. Globalização e educação: demonstrando a existência de uma "cultura educacional mundial comum" ou localizando uma "agenda globalmente estruturada para a educação". Educação \& Sociedade, Campinas, v. 25, n. 87, p. 423-460, maio/ago. 2004. DOI: $10.1590 / \mathrm{s} 0101-73302004000200007$

DAOLIO, J. Educação Física escolar: uma abordagem cultural. In: PICCOLO, V. L. N. (Org.). Educação Física escolar: ser... ou não ter?. Campinas: Unicamp, 1993. p. 49-57.

DAOLIO, J. Da cultura do corpo. São Paulo: Papirus, 1994.

DAOLIO, J. Educação Física e o conceito de cultura. Campinas, SP: Autores Associados, 2007.

FAUSTINO, R. C. Política educacional nos anos de 1990: o multiculturalismo e a interculturalidade na educação escolar indígena. 2006. 330 f. Tese (Doutorado em Educação) Universidade Federal de Santa Catarina, Florianópolis, 2006.

FONSECA, M. O Banco Mundial como referência para a justiça social no terceiro mundo: evidências do caso brasileiro. Revista da Faculdade de Educação, São Paulo, v. 24, n. 1, p. 37 69, jan./jun. 1998. DOI: 10.1590/s0102-25551998000100004

FREIRE, J. B. Educação de corpo inteiro: teoria e prática da Educação Física. São Paulo: Scipione, 1989.

GEERTZ, C. A interpretação das culturas. Rio de Janeiro: LCT, 2011.

HARVEY, D. O enigma do capital: e as crises do capitalismo. Boitempo, 2012.

HARVEY, D. Condição pós-moderna: uma pesquisa sobre as origens da mudança cultural. 13. ed. São Paulo: Loyola, 2004.

HILDEBRANDT, R.; LAGING, R. Concepções abertas no ensino da educação física. Rio de Janeiro: Ao Livro Técnico, 1986.

KUNZ, E. Transformação didático-pedagógica do esporte. Ijuí: Unijuí, 1994.

LEONTIEV, A. N. Actividad, conciencia, personalidad. La Habana: Editorial Pueblo y Educación, 1981.

LEONTIEV, A. O desenvolvimento do psiquismo. São Paulo: Centauro, 2004. 
LUKÁCS, G. Prolegômenos para uma ontologia do ser social. São Paulo: Boitempo, 2010.

MARX, K.; ENGELS, F. A Ideologia Alemã. Rio de Janeiro: Civilização Brasileira, 2007.

MARX, K. Sobre a questão judaica. São Paulo: Boitempo, 2010.

MEDINA, J. P. S. A educação física cuida do corpo... e "mente": bases para a renovação e transformação da educação física. Campinas: Papirus, 1983.

MÉSZÁROS, I. A educação para além do capital. São Paulo: Boitempo, 2008.

MÉSZÁROS, I. A crise estrutural do capital. São Paulo: Boitempo, 2009.

NETTO, J. P. Introdução ao estudo do método de Marx. São Paulo: Expressão Popular, 2011.

NETTO, J. P.; BRAZ, M. Economia política: uma introdução crítica. 3. ed. São Paulo: Cortez, 2007.

OLIVEIRA, V. M. Educação Física humanista. Rio de Janeiro: Ao Livro Técnico, 1985.

OLIVEIRA, R. C.; DAOLIO, J. Educação Física, cultura e escola: da diferença como desigualdade à alteridade como possibilidade. Revista Movimento, Porto Alegre, v. 16, n. 1, p. 149-167, jan./mar. 2010.

SILVA, U. B. Racismo e alienação: Uma aproximação à base ontológica de temática racial. São Paulo: Instituto Lukács, 2012.

SOARES, C. L. et al. Metodologia de ensino da educação física. São Paulo: Cortez, 1992.

TAFFAREL, C. N. Z. A formação do profissional da educação: o processo de trabalho pedagógico e o trato com o conhecimento no curso de Educação Física. 1993. 230 f. Tese (Doutorado em Educação) - Universidade Estadual de Campinas, Campinas, 1993.

TANI, G. et al. Educação Física escolar: fundamentos de uma abordagem desenvolvimentista. São Paulo: EDUSP, 1988.

TONET, I. Educação contra o capital. Maceió: Edufal, 2007.

UNESCO. Organização das Nações Unidas para a Educação, a Ciência e a Cultura. Declaração dos princípios de cooperação cultural internacional. 1966. Disponível em: <http://www.dhnet.org.br/direitos/sip/onu/cultura/coop96.htm>. Acesso em: 20 ago. 2011.

UNESCO. Organização das Nações Unidas para a Educação, a Ciência e a Cultura. Nossa diversidade criadora: relatório da comissão mundial de cultura e desenvolvimento. Campinas: Papirus, 1997.

UNESCO. Organização das Nações Unidas para a Educação, a Ciência e a Cultura. Declaração universal sobre a diversidade cultural. 2002. Disponível em: <http://unesdoc.unesco.org/images/0012/001271/127160por.pdf>. Acesso em: 10 ago. 2010. 
VYGOTSKY, L. S. A formação social da mente. São Paulo: Martins Fontes, 1984.

VYGOTSKY, L. S. Pensamento e linguagem. São Paulo: Martins Fontes, 1987.

Recebido em 31/05/2016

Versão final recebida em 11/02/2017

Aceito em 15/02/2017 